\title{
Assessment of Potential Negative Impact of the System of Factors on the Ship's Operational Condition During Transportation of Oversized and Heavy Cargoes
}

\section{Svitlana Onyshchenko, Olexandr Shibaev, Oleksiy Melnyk}

The potential risks to vessels and crew in merchant shipping stem from human error, vulnerability to environmental influences, failure of shipboard systems and equipment. In case of transportation of heavy and oversized cargo, the preceding list can be expanded to include potential hazards directly associated with the cargo. This study identified a system of potential negative events in the transportation of oversized and heavy cargo under the influence of multiple factors. Negative events are divided into two categories: those occurring during loading/unloading and those occurring during transportation. The consequences of these negative events for cargo and operational condition of the ship are also identified. Six basic options for the operational

\section{KEY WORDS}

$\sim$ Ship operational condition

$\sim$ Transportation process

$\sim$ Negative impact and consequences

$\sim$ Seaworthiness

$\sim$ Probability

Odessa National Maritime University, Odessa, Ukraine

e-mail: onyshenko@gmail.com

doi: 10.7225/toms.v10.n01.009

This work is licensed under (cc) BY

Received on: Mar 23, 2020 / Revised on: Sep 23, 2021 / Accepted on:Dec 9, 2021 / Published online: Feb 1, 2021 condition of the vessel in the transportation process of oversized and heavy cargo have been determined. The conceptual model of the combination of factors affecting the operational condition of the vessel during the transportation of oversized and heavy cargo is formulated, and the chain of formation of the probability of negative events during the transportation of oversized and heavy cargo is identified and mathematically described. A basic pattern of relationship between various negative events occurring during transportation of oversized and heavy cargoes and ship's operational conditions is established. The obtained results allow the probability of possible negative events and change of ship's condition due to such influences during the transportation of the cargo category concerned to be estimated in practice, taking into account the specifics of a particular port, vessel and shipping line.

\section{INTRODUCTION}

Shipping is an activity with a rather high level of potential risks, primarily due to the "aggressiveness" of the water environment and considerable influence of weather conditions, which can vary widely even within one voyage. In addition, being complex technical systems, ships are subject to possible failures of different equipment, devices and systems. This is compounded by the risk of "human error" and potential mistakes by the crew, both in normal voyage conditions and under the negative influence of adverse weather conditions. Thus, apart 
from potential risks for ship and crew caused by the human factor and arising from the ship's vulnerability to environmental impact, technical failures of systems and equipment, there are also potential dangers associated with damage, shifting or loss of deck cargo during transportation of oversized and heavy cargoes

Ensuring safe conditions for the transportation of oversized and heavy cargoes is a major issue in terms of the safe operation of ships and improving the quality and efficiency of maritime transport. The problem takes on a completely different dimension when it comes to the organization of deck cargo transportation of non-standard cargoes, as this type of transportation is particularly subject to the problem of shifting cargo, and further damage to or loss of cargo. The basic criteria for safe stowage and securing of deck cargoes are outlined in the regulatory and technical documents, but thorough monitoring of the "ship-cargo" object is always a priority task that needs a complex analysis. Control of parameters and characteristics ensuring the safety of the vessel during the transportation of deck cargo is a real problem that requires comprehensive study and systematic approach.

Given that the transportation of oversized and heavy cargo by sea is unique in most respects, well known and proven technologies and procedures applying to the carriage of, e.g. bulk goods, are practically impossible to apply to the transportation of the said category of commodities.

Thus, the operation of dry cargo vessels for the transportation of oversized and heavy cargoes $(\mathrm{OHC})$, contrary to their utilization for shipping of traditional bulk cargoes, is characterized by a higher degree of dependence of the operational condition of the vessel on the condition of cargo. In the context of cargo deployment on board the vessel, compliance with certain rules and regulations for stowage (including loads on the deck and hull), as well as the condition of the securing systems and equipment and their location, ensure the stability of cargo during voyage. All items listed herein are directly connected with the widespread tendency of cargo to shift during transportation due to, e.g. wind pressure, slack or breakage of securing devices and accessories as a result of crew negligence or adverse weather conditions, inadequate quality of securing materials or incorrect calculations of breaking strength relative to the mass-dimension characteristics of the cargo, and so on.

\section{LITERATURE OVERVIEW AND PROBLEM FORMULATION}

A significant number of papers studied risks in shipping in terms of the impact of negative factors on the transportation process. Extensive statistical analysis of various kinds of accidents in maritime transport is presented in (Schneider et al., 1999; Eliopoulou et al., 2016). In Bužančić Primorac and Parunov (2016), the dynamics of the main types of accidents in shipping were revealed and General Cargo, Bulk Carriers, Passenger and Fishing vessels were found to have the highest accident rates. An analysis and models of accidents in specific shipping lanes in terms of their specifics are presented in Kim et al., (2011), Mou et al., (2015) and Ramin et al., (2020). Particularly, in Kim et al. (2011) the results of probabilistic analysis are given for Mokpo waterways and in Mou et al., (2015) for Shenzhen Waters. In Ramin et al., (2020) risk prediction models based on time series analysis are presented for Port Klang and the Straits of Malacca. An evaluation of ship performance under varying operational conditions and ship operational efficiency were reviewed in papers (Perera et al., 2015; Aldou, 2015). In Soner et al., (2018), preliminary data were studied, and an analysis of a selected vessel was conducted to monitoring its performance along the ship routes studied. Some papers presented methods of risk analysis, taking into account the specifics of infrastructure (Yoo and Kim; 2019) and traffic (Guze and Kołowrocki, 2017), and in Bužančić Primorac et al., (2020), a probabilistic model of damage to the ship's hull was developed. The analysis of recent publications led us to conclude that, as a rule, regression models are used to establish the influence of factors in shipping (for example, Petersen et al., (2011), Onyshchenko et al., $(2015 ; 2016))$, while models based on the Markov processes are used to assess potential risks (Peel and Good, 2011; Girtler, 2013; Onyshchenko and Melnyk, 2020). In particular, in Girtler, (2013) the Markov model of the accident of ships at the entrance into and exit from the port is presented; in Onyshchenko and Melnyk (2020) the Markov model of the change in the operational state of the ship during the transportation of heavy and oversized cargo is investigated. It is worth noting that maritime transportation of heavy and oversized cargo is given negligible attention in modern studies. Among the few dealing with the subject, CSS code (1991) deserves special mention as it provides the main principles for the organization of transportation, stowage and securing of oversized project cargoes. Effectiveness assessment of non-specialized vessel acquisition and operation projects, with respect to their suitability for oversized cargo transportation, includes issues related to the cargo loading and stowage matters studied in Melnyk and Malaksiano (2020). Thus, the issues of risk assessment based on the construction of probabilistic models have practically not been studied for the type of maritime transportation concerned. The practical implementation of the Markov model (Onyshchenko and Melnyk, 2020) requires the methods for the assessment of both the initial state probabilities and potential changes of the ship condition to be identified, taking into account the specifics of heavy and oversized cargo transportation. There is clearly a need for relevant research of this topic and would be of great importance.

Therefore, the purpose of this study is to identify the system of factors at various stages of maritime transportation of heavy and oversized cargo which would serve as the basis for the development of a probabilistic model of effect of potential negative events on the ship's operational condition. This would, in 
practice, allow the assessment of potential risks during maritime transportation of this cargo category, taking into account the specifics of a particular port, vessel and shipping lane.

Negative events and their consequences during the transportation of oversized and heavy cargoes

The negative impact on the ship's operational condition or, more precisely, the probability of such impact occurring during the transportation of non-standard cargo or cargo increases over time, which is not typical for ship specialization. At the same time, the following factors have a significant impact:

- the level of competence and relevant experience of both the ship's crew and the stevedores performing loading/ unloading activities;

- weather conditions during cargo operations and during transportation;

- seaworthiness of the vessel relative to the specified weather conditions during transportation;

- quantity and quality of securing equipment and separation materials.

The assessment of the potential negative impact of a combination of random factors on a ship's operational condition is a major challenge in ensuring proper operational condition of a ship during $\mathrm{OHC}$ transportation. The following conceptual model is proposed to achieve this goal (Figure 1).

The combination of factors of various origin may lead to the occurrence of random events that could potentially endanger a ship's operational condition:

$A_{1}(i=\overline{1, n})$ - in the loading stage;

$c_{k}(k=\overline{1, K})$ - during transportation;

$E_{I}(I=\overline{1, L})$ - in the unloading stage.

Probabilities of above events: $P\left(A_{1}\right), i=\overline{1, n} ; k=\overline{1, K} ; P\left(E_{l}\right), I$

$=\overline{1, L}$; If we assume that these events are all negative events that may occur during loading/transportation/unloading, and that they are independent and joint, such events form a complete group, and therefore:

$\sum_{i=1}^{n} P\left(A_{i}\right)+\sum_{k=1}^{K} P\left(C_{k}\right)+\sum_{l=1}^{L} P\left(E_{l}\right)=1$

"Potential hazard" means that risk to the ship's operational condition may be hidden and appear after a certain time. For example, excessive load on deck can have negative consequences for the ship's operational condition, either directly during transportation, in combination with the impact of adverse weather conditions or in itself. Negative consequences may appear after unloading, or not at all - for example, in spite of deck load limits being exceeded, no negative consequences for the vessel were detected after the cargo was unloaded (local strength was exceeded, but that did not result in deformation, destruction, etc.).
Thus, the occurrence of events $A_{1}(i=\overline{1, n})$ could result in random events $B_{1}(i=1, \bar{n})$ or not, i.e. events $\overline{B_{1}}(i=\overline{1, n})$ take place. In this study, we believe that only one event $A_{1}(i=\overline{1, n})$ corresponds to each of the following $B_{1}(i=\overline{1, n})$, subject to their aggregated review. Decomposition and detail $A_{1}(i=\overline{1, n})$ and $B_{1}(i=\overline{1, n})$ allow more complex interactions to be considered and explored, for example, if an event $B_{1}(i=\overline{1, n})$ can only occur if several events occur simultaneously $A_{1}(i=\overline{1, n})$ etc.

In addition, these events $A_{1}(i=\overline{1, n})$ can take place simultaneously, hence event $\bigcup_{i=1}^{n} A_{i}$ may occur and trigger event $\bigcup^{n} B_{i}$

It is worth noting that according to the shipping and ship operation practice (as emphasized above), some consequences of events $A_{1}(i=\overline{1, n})$ may occur, for example, during transportation (sea passage between ports), i.e. some consequences, for example, $\bigcup^{\mathrm{n}} \mathrm{B}_{\mathrm{i}}$ may occur during cargo operations, and some, for example, $\mathrm{UB}^{\mathrm{n}}$ during transportation.

Since events $B_{1}(i=\overline{1, n})$ depend on $A_{1}(i=\overline{1, n})$, the probability of events $B_{1}(i=\overline{1, n})$ - is actually the probability of these events in case of occurrence of $A_{1}(i=\overline{1, n})$ that is, conditional probability $\mathrm{P}_{\mathrm{A}_{\mathrm{i}}}\left(B_{1}\right), i=\overline{1, n}$. Respectively, the probabilities of events $\overline{B_{1}}(i=\overline{1, n})$ :

$P_{A_{i}}\left(\overline{\left.B_{i}\right)}=+1-P_{A_{i}}\left(B_{i}\right), i=\overline{1, n}\right.$

Similar to the probability of negative consequences $D_{k}(k=\overline{1, K})$ and $\left.F_{I}(I=\overline{1, L}): P_{C_{k}}\left(D_{k}\right), k=\overline{1, K}\right)$ and $\left.P_{E_{l}}\left(F_{l}\right), I=\overline{1, L}\right)$.

Thus, during loading, there is a probability of negative consequences for the ship's operational condition:

$\sum_{i=1}^{n^{\prime}} P\left(A_{i}\right) \cdot P\left(A_{i}\right) B_{i}$

during transportation

$\sum_{i=n^{\prime}+1}^{n} P\left(A_{i}\right) \cdot P\left(A_{i}\right) B_{i}+\sum_{k=1}^{k} \cdot P\left(C_{k}\right) \cdot P\left(C_{k}\right) D_{k}$

during unloading

$\sum_{l=1}^{L} P\left(E_{l}\right) \cdot P\left(E_{l}\right) F_{l}$

Thus, there is a probability of events that could endanger the ship's operational condition during $\mathrm{OHC}$ transportation: 


$$
\begin{aligned}
\sum_{i=1}^{n} P\left(A_{i}\right) \cdot P_{A_{i}}\left(B_{i}\right)+\sum_{k=1}^{K} P\left(C_{k}\right) & \cdot P_{C_{k}}\left(D_{k}\right) \\
& +\sum_{l=1}^{L} P\left(E_{l}\right) \cdot P_{E_{l}}\left(F_{l}\right)
\end{aligned}
$$

Based on the synthesis of practical experience with the transportation of oversized and heavy cargo on bulk carriers and dry cargo ships (i.e. ships not specialized for these cargo categories), the following events were identified (Table 1, 2).
In particular, statistical data, expert estimates and the general experience of maritime shipping, insurance and survey companies were used to identify the aggregate of negative events and their consequences. So we assume $A_{1}(i=\overline{1, n})$ - in the loading stage and $C_{k}(k=1, K)$ - during transportation, and their consequences for the ship's operational condition $B_{1}(i=\overline{1, n})$ and $D_{k}(k=\overline{1, K})$. In this case, the events $E_{l}(I=\overline{1, L})-$ in the unloading stage, thus we assume that the events in the loading stage and their consequences are identical.

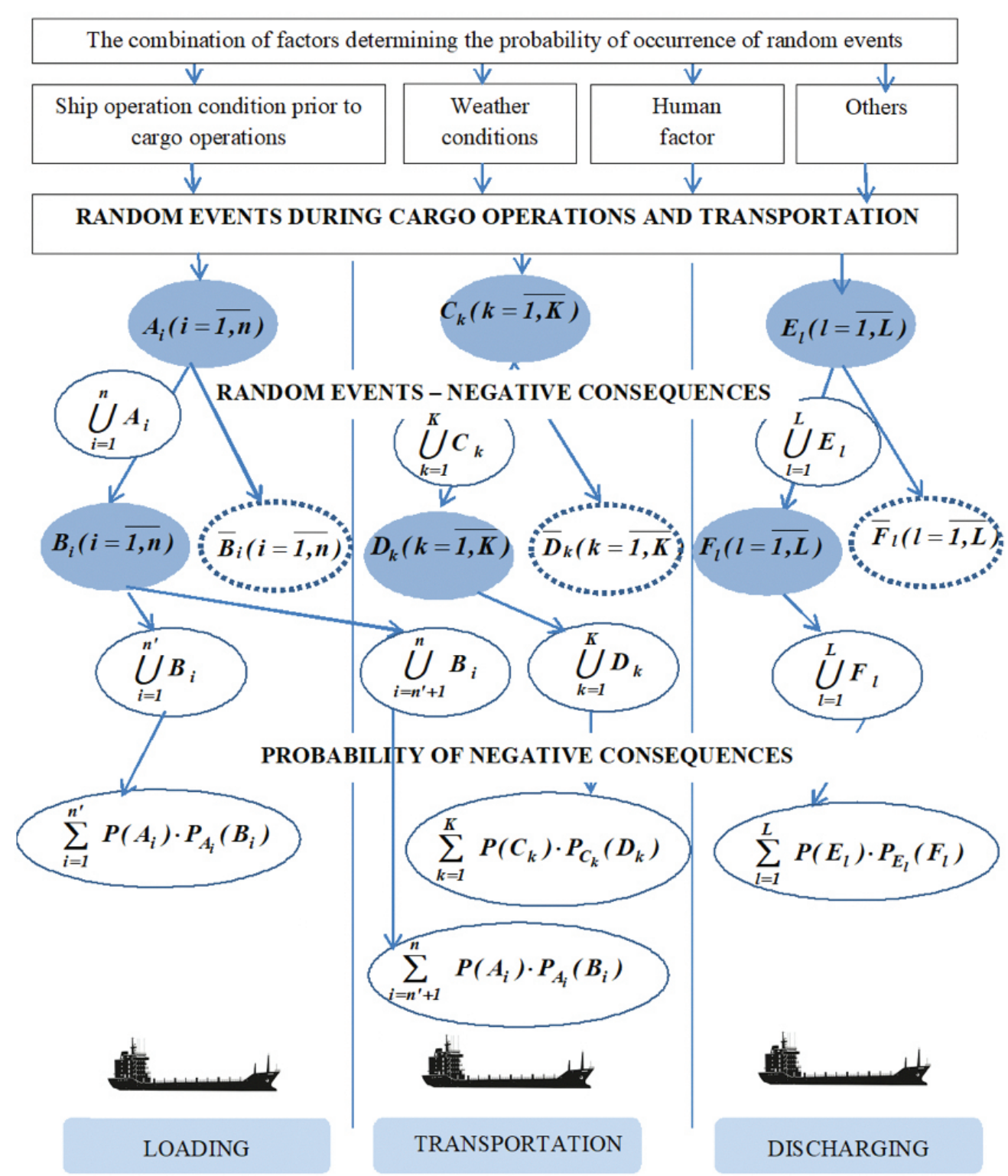

Figure 1.

Conceptual model of a combination of factors that have an effect on the ship's operational condition during the transportation of oversized and heavy cargoes. 
Table 1.

Negative events and their consequences during the loading of oversized and heavy cargo.

\section{Negative events $A_{1}(i=\overline{1,9})$}

A1. Insufficient level of ship crew's competence, lack of practical skills and experience with $\mathrm{OHC}$ transportation;

A2. Breach of safety precautions during cargo operations like $\mathrm{OHC}$ hoisting, handling and stowage;

A3. Inadequate load on the ship's cargo gears, critical lifting angles and rough maneuvers under load;

A4. Malfunctioning of deck cargo loading and stowage technology, exceeding of a ship's local strength limitations;

A5. Poor quantitative and qualitative characteristics of securing equipment and separation material;

A6. Absence of regular stability calculations, periodic ballast tank sounding and ballast system operation during deck cargo loading;

A7. Breakage of deck cargo loading stowage and securing technologies, non-compliance with the requirements of the IMO Code of Safe Practice for Ships, when transporting deck cargo;

A8. Restrictions of existing methods and rules for securing deck cargo, given its weight-dimensional structure;

A9. Absence of quality standard certificates for lashing equipment and separation materials;

\section{Consequences $B_{1}(i=\overline{1,9})$}

B1. Lack of adequate supervision and monitoring of cargo operations, cargo stowage and securing, inability to prevent and respond to emergency situations;

B2. Damages to the ship' s structural elements, deck equipment and hatch cover arrangements;

B3. Emergency situations with ship's cargo gears, damage to electrical and mechanical parts, breakage of running rigging elements;

B4. Damage to the ship's structural elements, decks, hatch covers;

B5. Damage to the ship's structural elements, decks, hatch covers. Cargo damage, destruction of framing packaging, supports and platforms.

B6. Sudden occurrence of heel/list, emergency situations involving cargo gears and cargo during cargo operations;

B7. Increase of lateral area, constrained maneuverability in stormy weather conditions, insufficient ship stability.

B8. Overestimation of cargo securing costs, increased labor intensity of the cargo securing process, cargo handling time;

B9. Untimely deterioration, breakdown and destruction of cargo securing systems, damage and loss of cargo;

Table 2.

Negative events and their consequences during the transportation of oversized and heavy cargo.

Negative events $C_{k}(k=\overline{1,11})$

C1. Human factor - incorrect assessment of weather conditions;

C2. Incompetent ship handling and maneuvering in adverse weather conditions;

C3. Lack of proper and regular supervision of the condition of cargo securing systems during the sea passage;

C4. Absence of a certified weather routing service during the sea passage;

C5. Not taking weather forecasts and prevailing conditions into account while pre-planning the ship's passage;
Consequences $D_{k}(k=\overline{1,11})$

D1. Damage or loss of deck cargo leading to damage to and loss of ship;

D2. Destruction of securing systems, damage or loss of deck cargo and the resulting damage to and loss of the ship;

D3. Loosening and slackening of the cargo securing system, broken and destroyed lashings. Shifting, damage and loss of cargo;

D4. Deck cargo moving and shifting due to the influence of dynamic loads while sailing in adverse weather conditions;

D5. Deck cargo shifting due to the influence of dynamic loads during transportation in adverse weather conditions; 
A multitude of potential conditions of an observed object depend on the specificity of the object and the problem under consideration. Thus, the condition of a ship, similar to that of an aircraft, for example, studied in Petersen et al., (2011) and Onyshchenko and Yu (2015), can be considered aggregated, i.e. the following conditions can be identified: operable condition, defective operable condition, defective inoperable condition. On the other hand, a ship can be represented as a combination of different systems, in which case its condition can be described by a combination of conditions of these multiple systems.

It should be noted that a ship's operational condition in the context of the task being solved, cannot be identified as "operable", "defective operable" or "defective not operable", which is determined by the presence of different condition options in the framework of "defective operable".

A ship's operational condition can be clearly determined for purposes of its evaluation during $\mathrm{OHC}$ transportation, by representing the condition of the object under study - the ship in the process of transportation - as a condition of a complex of two objects "ship-cargo". The final operational condition of the ship during transportation is determined taking into account various events directly related to the ship (for example, technical system failure) or its cargo, (cargo shifting and negative impact on the deck, etc.).

Further identification of the principal conditions of the "ship-cargo" object under study is proposed to be achieved by breaking down the specified condition into two options ("normal", "having problems") based on three components: "seaworthiness", "ship performance", "cargo stowage and securing". This approach primarily depends on the specifics of ship operation during $\mathrm{OHC}$ transportation, for example, unusual methods of cargo stowage and securing, which may cause incidents during cargo handling in the port, as well as impair the "integrity" of the "ship-cargo" object during transportation.

The following basic options for ship condition (Table 3) have been derived from the positive ("in norm" - 1) and negative (" problem presence" - 0) assessment of each component. The practical experience of ship-owning and operating companies engaging in international transportation and the analysis of accident-related statistics have also been used to determine the potential operational condition of ships.

Table 3

Main operational conditions during the transportation of oversized and heavy cargoes.

\begin{tabular}{lllll} 
Condition & Seaworthiness & Ship performance & $\begin{array}{l}\text { Cargo stowage and } \\
\text { securing }\end{array}$ & Description \\
\hline S1 & $\mathbf{1}$ & $\mathbf{1}$ & $\mathbf{1}$ & Satisfactory operational condition; \\
\hline S2 & $\mathbf{1}$ & $\mathbf{1}$ & $\mathbf{0}$ & Cargo loss/damage; \\
\hline S3 & $\mathbf{1}$ & $\mathbf{0}$ & $\mathbf{0}$ & $\begin{array}{l}\text { Damage/loss of cargo damaged the ship's } \\
\text { structural elements and deck equipment; }\end{array}$ \\
\hline S4 & $\mathbf{1}$ & $\mathbf{0}$ & $\mathbf{1}$ & $\begin{array}{l}\text { Damage to the ship's structural elements and } \\
\text { deck equipment as a result of moving/shifting } \\
\text { cargo/destruction of securing devices; }\end{array}$ \\
\hline S5 & $\mathbf{0}$ & $\mathbf{1}$ & $\mathbf{N}$ & $\begin{array}{l}\text { Negative initial stability, critical angle of heel, } \\
\text { cargo shifting, destruction of securing systems; }\end{array}$ \\
\hline S6 & $\mathbf{0}$ & $\mathbf{0}$ & $\mathbf{0}$ & Emergency operational condition \\
\hline
\end{tabular}

It is noteworthy that two theoretically feasible options: satisfactory condition of cargo under unsatisfactory performance and seaworthiness of the ship (combination of 0.0.1), and the loss of seaworthiness and unsatisfactory condition of cargo under normal performance (0.1.0), make no practical sense and actually turn into (0.0.0) - i.e. unsatisfactory condition of the ship and cargo.
The following interrelations of events and conditions (Table 4), schematically presented in Figure 2, have been obtained by summarizing practical experience and following the logic of interrelation of negative impacts on operational condition. 
Kim, K.-I., Park, G.-K. \& Jeong, J.-S., 2011. Analysis of marine accident probability in Mokpo waterways. Journal of Navigation and Port Research, 35(9), pp.729-733. Available at:

http://dx.doi.org/10.5394/kinpr.2011.35.9.729.

Melnyk, O., \& Malaksiano, M., 2020. Effectiveness Assessment of Non-Specialized Vessel Acquisition and Operation Projects, Considering Their Suitability for Oversized Cargo Transportation. Transactions on Maritime Science, 9(1), pp. 23-34. Available at:

https://doi.org/10.7225/toms.v09.n01.002.

Mou, J., Chen, P. \& Li, Y., 2015. Risk analysis of maritime accidents in an estuary: a case study of Shenzhen Waters. Scientific Journals of the Maritime University of Szczecin, 114 (42), pp. 54-62.

Onyshchenko S. \& Koskina, Y., 2015. Research of the effect of terms and conditions of an offer on successful conclusion of the freight transaction. Eastern-European Journal of Enterprise Technologies, 6(3(78)), p.25. Available at: http://dx.doi.org/10.15587/1729-4061.2015.55738.

Onyshchenko, S., Koskina, Y. \& Savelieva, I., 2016. Developing a logit model for the provision of the process of managing the conclusion of voyage chartering transactions. Eastern-European Journal of Enterprise Technologies, 6(3 (84)), pp.2631. Available at:

http://dx.doi.org/10.15587/1729-4061.2016.85233.

Onyshchenko, S., \& Melnyk, O., 2020. Modelling of changes in ship's operational condition during transportation of oversized and heavy cargo. Technology audit and production reserves, $6(2$ (56)), pp. 66-70. Available at: https://doi.org/10.15587/2706-5448.2020.221653.
Peel, D. \& Good, N.M., 2011. A hidden Markov model approach for determining vessel activity from vessel monitoring system data T. Quinn II, ed. Canadian Journal of Fisheries and Aquatic Sciences, 68(7), pp.1252-1264. Available at: http://dx.doi.org/10.1139/f2011-055.

Perera, L.P. et al., 2015. Evaluations on Ship Performance Under Varying Operational Conditions. Volume 7: Ocean Engineering. Available at: http://dx.doi.org/10.1115/omae2015-41793.

Petersen, J. P. et al., 2011. Gaussian Mixture Models for Analysing Operational Ship Data.

Ramin, A., Mustaffa, M. \& Ahmad, S., 2020. Prediction of Marine Traffic Density Using Different Time Series Model From AIS data of Port Klang and Straits of Malacca. Transactions on Maritime Science, 9(2). Available at:

http://dx.doi.org/10.7225/toms.v09.n02.006.

Schneider, T., Armingaud, F. \& Tabarre, M., 1999. Statistical Analysis of Accident Data Associated with Sea Transport (Data from 1994-1997). Rep. CEPN-IPSN, NTE/99/02. Institut de Protection et de Surete Nucleaire. Fontenay-aux-Roses.

Soner, O., Akyuz, E. \& Celik, M., 2018. Use of tree based methods in ship performance monitoring under operating conditions. Ocean Engineering, 166, pp.302-310. Available at:

http://dx.doi.org/10.1016/j.oceaneng.2018.07.061.

Yoo, Y. \& Kim, T.-G., 2019. An Improved Ship Collision Risk Evaluation Method for Korea Maritime Safety Audit Considering Traffic Flow Characteristics. Journal of Marine Science and Engineering, 7(12), p.448. Available at: http://dx.doi.org/10.3390/jmse7120448. 